\title{
BEHAVIORAL ORIGIN OF TREMULATION, AND POSSIBLE STRIDULATION, IN GREEN LACEWINGS (NEUROPTERA: CHRYSOPIDAE) ${ }^{1}$
}

\author{
By Peter Duelli ${ }^{2}$ and James B. Johnson ${ }^{3}$ \\ University of California, Berkeley, \\ Division of Biological Control \\ 1050 San Pablo Ave. \\ Albany, CA 94706 USA
}

\section{Introduction}

Abdominal vibration or "jerking" in connection with courtship behavior has been described for several green lacewing species (e.g. Smith 1922; Toschi 1965; Tauber 1969; Sheldon and MacLeod 1974) and explored in detail by Henry $(1979,1980 a, b, c)$. In Chrysoperla carnea (Stephens) isolated individuals produce long, patterned sequences of discrete short bursts of rhythmic vibration of the abdomen in the vertical plane. The wings may also vibrate. Sexually receptive pairs establish duets of reciprocal abdominal jerking. Actual drumming of the abdomen on the substrate does not occur. It had been assumed that abdominal vibration produces high-frequency sounds by stridulation (Adams 1962, Riek 1967, Eichele and Villiger 1974, Henry 1979) and acoustical communication was discussed in connection with the tympanal ultrasound receptor organ described by Miller $(1970,1971)$. Courtship and copulation take place on the vegetation, usually on the underside of leaves. Henry $(1980 \mathrm{a}, \mathrm{c})$ in his work with Chrysoperla spp. demonstrated that communication is performed via low-frequency substrate vibration and not by airborne sound. Males were able to establish duets with females within a range of $15 \mathrm{~cm}$. According to Henry (1980a, b, c), differences in the vibration patterns of Chry-

'Published with the approval of the Director of the Idaho Agricultural Experiment Station as Research Paper No. 81613.

2Present address: Zoologisches Institut, Universität Basel, Rheinsprung 9, 4051 Basel Switzerland.

${ }^{3}$ Present address: Department of Entomology, University of Idaho, Moscow, Idaho 83843 U.S.A.

Manuscript received by editor December 15, 1981. 
soperla rufilabris (Burmeister), C. downesi (Banks) and C. carnea suggest that "acoustical" communication may help to reproductively isolate sympatric lacewing species.

Since the vibration produced by abdominal jerking in lacewings seems to be propagated in a transverse wave (perpendicular to the plane of the substrate) we prefer to call this type of communication "tremulation", following Busnel et al. (1956), Henry (1980c) and Morris (1980). On the other hand, sound in the form of longitudinal waves, is produced by stridulation and percussion. Possible stridulatory structures in lacewings were first described for the chrysopid Meleoma schwarzi (Banks) by Adams (1962) and later for other Neuroptera (Riek 1967). However, to date, there is no reported record of any sound produced by these organs (Henry 1980c). In $M$. schwarzi, sound may be produced when the second abdominal sternite, with its regular striae of microtrichia, is rubbed against the femora by abdominal vibration (Adams 1962). C. carnea and some other species of Chrysopidae may stridulate using microtrichia on the venter of the anal lobe of the forewings and dorsolaterad on the metanotum (Riek 1967; Henry 1979). Alternatively, these paired areas of microtrichia may function to hold the wings in place when at rest (Henry 1980c). Thus, tremulation and possible stridulation are both produced by vibrating the wings and abdomen.

\section{Methods and Materials}

Observations of free flight and mating behavior were made on the following species: C. carnea, Eremochrysa punctinervis McLachlan, E. tibialis Banks, Mallada basalis (Walker), Meleoma hageni Banks and Nodita n. sp. The only specialized technique required for this study was the use of a strobe light to illuminate lacewings on a flight mill (Duelli 1980). By varying the frequency of the strobe flashes, it was possible to determine the rate of the wing beats and other body movements, as the highest flash frequency at which the motion appeared to be "frozen" and each structure was seen in only one position. A multiple of this frequency again produces a frozen image, but the body is seen in multiple positions. C. carnea and $M$. basalis were examined in this manner.

\section{Results}

Among the species observed, there appeared to be great variation in the patterns and intensities of vibration of the wings and abdomen during courtship, but this was not quantified. The beha- 
vior was strongly developed in species of the genera Meleoma and Eremochrysa, but was even more conspicuous in the Indo-Pacific lacewing M. basalis, as observed on the island of American Samoa. In this species, the males flapped their wings so vigorously that they hit the substrate and produced sounds easily perceptible to the human ear. Heavily developed pterostigmata in the hind wings of the male may enhance substrate vibration and protect the wings from damage (Fig. 1). During courtship, the males moved forward
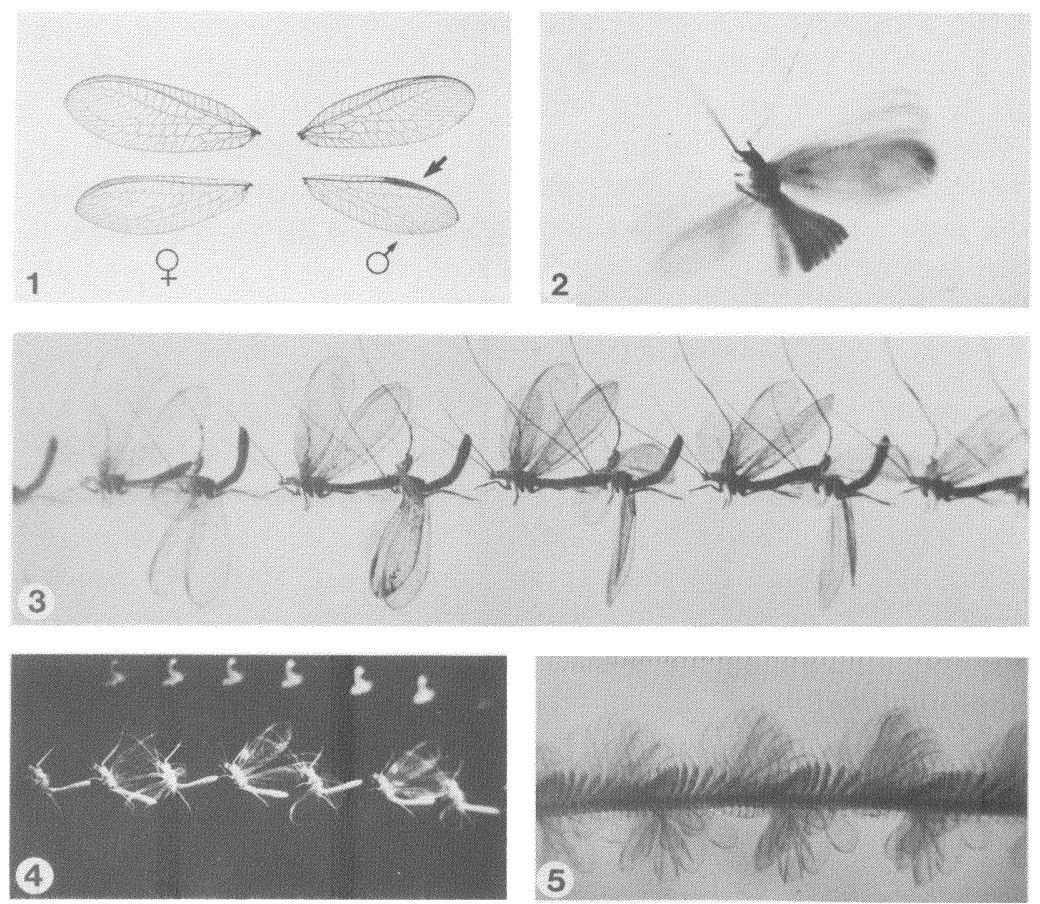

Figures 1-5. Fig. 1. Forewing and hind wing of female (left) and male (right) Mallada basalis. The arrow indicates the heavily developed pterostigma in the hindwing of the male. Fig. 2. Stationary flight of a tethered Chrysoperla carnea male. Strobe flashes $(60 \mathrm{~Hz}$, exposure $0.25 \mathrm{sec})$ show the extent of the abdominal motion. Fig. 3. Chrysoperla carnea male mounted horizontally on a flight mill. Strobe flashes $(54 \mathrm{~Hz})$ show the exact antiphase of abdominal and wing vibration. Fig. 4. Chrysoperla carnea male mounted on a flight mill in "natural" flight position as shown in figure 2. Any forced deviation from the "natural" body angle leads to an increased amplitude of the abdominal vibration (See figure 3 for comparison). Fig. 5. Same specimen and same position as in Fig. 3. $400 \mathrm{~Hz}$ strobe flashes show the full flow of the movements of wings and abdomen. 
and backward in front of the female, and sometimes even sideways. Especially vigorous males were seen to perform small jumps, reminiscent of take-off behavior.

A chrysopid usually flies with its head higher than its abdomen. If the insect is mounted on a flight mill and illuminated with a strobe light, the abdomen can be seen moving up and down in the same way as described for the courtship behavior (Fig. 2). When mounted horizontally, the abdominal movements were exaggerated (Fig. 3). In both orientations the strobe flashes revealed that the frequencies of the wing beat and of the abdominal vibration were the same. With each down-stroke of the wings the abdomen was lifted (Figs. 3 and 4). The flow of the movements can be seen in Fig. 5.

Observations made during this study indicate that the wing beat frequency was positively correlated with temperature and, in general, negatively correlated with wing length. At $23^{\circ} \mathrm{C}$, a wing beat frequency of $27 \mathrm{~Hz}$ (strokes/sec) was recorded for C. carnea and 38 $\mathrm{Hz}$ for the smaller $M$. basalis. Miller (1975) reported similar results, $25 \mathrm{~Hz}$ at $21-24^{\circ} \mathrm{C}$ in tethered flying $C$. carnea.

\section{Discussion}

The frequencies of abdominal vibration during courtship have been reported for three species of Chrysoperla. For C. rufilabrus the rates were $14-18 \mathrm{~Hz}$ (Henry 1980a). No temperature data were given. In $C$. carnea the frequencies varied from 30 to $100 \mathrm{~Hz}$ at 24-28 ${ }^{\circ} \mathrm{C}$ (Henry 1980c), while the courtship behavior of $C$. downesi included volleys of abdominal vibration with a frequency of 60-80 $\mathrm{Hz}$, with a mean of approximately $73 \mathrm{~Hz}$, at $24-29^{\circ} \mathrm{C}$ (Henry 1980b).

The greater variability in the frequencies of abdominal vibration during courtship, relative to flight, is probably related to two factors. First, there is no minimum rate of wing beats necessary to maintain flight. Second, the maximum possible rate is increased, since the wings merely vibrate rather than making full strokes. These would open a wide range of frequencies for chrysopids to use in tremulation. If character displacement occurred, as hypothesized by Henry (1980b), this would tend to expand the range of frequencies actually used by chrysopids.

Tremulation has also been reported in the courtship behavior of other groups of insects. Plecoptera communicate via the substrate by drumming with their abdomens (Rupprecht 1968). Similar 
drumming and/or abdominal vibration is known from certain Psocoptera (Pearman 1928), Orthoptera (refs. in Rupprecht 1968 and Morris 1980), Megaloptera (Rupprecht 1975) and Mecoptera (Rupprecht 1974). Wing fluttering is also involved in courtship of Panorpa spp. (Mecoptera) (Rupprecht 1974) and three genera of Coniopterygidae (Johnson and Morrison 1979).

The function of the abdominal motion in flight is unknown. In the Diptera, the halteres (modified second pair of wings) have been shown to act as specialized organs to maintain flight stability (Pringle 1948). They vibrate in a vertical or nearly vertical plane and, as gyroscopic indicators, reveal any change in the spatial orientation of the thorax via sensors at their bases. The halteres vibrate with the same frequency as the wings, but in antiphase. Since the same is true for the abdominal movements in lacewings, it is tempting to regard their abdominal vibration as an analogous gyroscopic mechanism to stabilize the orientation of the thorax during the slow hovering flight, thus keeping the insect in an upright position with regard to the horizontal plane. This possibility is supported by the similar orientation and abdominal movements of flying Plecoptera, Megaloptera (Sialis spp. and Neohermes sp.) and Mecoptera (Panorpa spp.) as observed in the field.

Indirect morphological evidence also supports this possibility. Whereas most other nocturnal insects have large ocelli, chrysopids and most other Neuroptera lack ocelli. An important function of the ocelli in locusts and other insects is to recognize relative changes in the height of the horizon (Taylor 1981) and thus to stabilize the flight position.

Based on the similarities between abdominal vibration during flight and courtship behavior, we suggest that tremulation behavior in lacewings and perhaps other slow-flying insects may have evolved from a particular "pre-adapted" feature in the take-off and flight behavior, where its main function might be flight stabilization.

\section{ACKNOWLEDGMENTS}

We wish to thank Dr. P. A. Adams for verifying the identifications of the species studied, Dr. K. S. Hagen for his helpful discussions and Dr. F. M. Carpenter for his suggestions regarding the manuscript. 


\section{Literature Cited}

Adams, P. A. 1962. A stridulatory structure in Chrysopidae (Neuroptera). Pan Pac. Entomol. 38(3): 178-180.

Busnel, R. G., B. Dumortier and M. C. Busnel. 1956. Recherche sur le comportement acoustique des éphippigères (Orthoptera: Tettigoniidae). Bull. Biol. Fr. Belg. 3: 219-286.

Duelli, P. 1980. Preovipository migration flights in the green lacewing, Chrysopa carnea. Behav. Ecol. Sociobiol. 7: 239-246.

Eichele, G. AND W. Villiger. Untersuchungen an den Stridulationsorganen der Florfliege Chrysopa carnea Steph. (Neuroptera: Chrysopidae). Int. J. Insect Morphol. Embryol. 3(1): 41-46.

HenRY, C. S. 1979. Acoustical communication during courtship and mating in the green lacewing, Chrysopa carnea. Ann. Entomol. Soc. Amer. 72(1): 68-79.

Henry, C. S. 1980a. Acoustical communication in Chrysopa rufilabrus (Neuroptera: Chrysopidae), a green lacewing with two distinct calls. Proc. Entomol. Soc. Wash. 82(1): 1-8.

HeNRY, C. S. 1980b. The courtship call of Chrysopa downesi Banks (Neuroptera: Chrysopidae): Its evolutionary significance. Psyche 86: 291-297.

HenRY, C. S. 1980c. The importance of low-frequency, substrate-borne sounds in lacewing communication (Neuroptera: Chrysopidae). Ann. Entomol. Soc. Amer. 73(6) 617-621.

Johnson, V. AND W. P. Morrison. 1979. Mating behavior of three species of Coniopterygidae (Neuroptera). Psyche 86: 395-398.

Miller, L. A. 1970. Structure of the green lacewing tympanal organ (Chrysopa carnea, Neuroptera). J. Morphol. 131: 359-382.

Miller, L. A. 1971. Physiological responses of green lacewings (Neuroptera: Chrysopidae) to ultrasound. J. Insect Physiol. 17: 491-506.

MoRris, G. K. 1980. Calling display and mating behavior of Copiphora rhinoceros Pictet (Orthoptera: Tettigoniidae). Anim. Behav. 28: 42-51.

Pearman, J. V. 1928 . On sound production in the Psocoptera and on a presumed stridulatory organ. Entomol. Monthly Mag. 64: 8-11.

Pringle, J. W. S. 1948. The gyroscopic mechanism of the halteres in Diptera. Phil. Trans. Roy. Soc. B. 233: 347-384.

RIEK, E. F. 1967. Structures of unknown, possible stridulatory, function on the wings and body of Neuroptera; with an appendix on other endopterygote orders. Austr. J. Zool. 15: 337-348.

Rupprecht, R. 1968. Das Trommeln der Plecopteren. Z. Vergl. Physiol. 59: 38-71.

RUPPRECHT, R. 1974. Vibrationssignale bei der Paarung von Panorpa. Experientia 30: $340-341$.

RUPPRECHT, R. 1975. Die Kommunikation von Sialis (Megaloptera) durch Vibrationssignale. J. Insect Physiol. 21: 305-320.

Sheldon, J. K. ANd E. G. MacLeod. 1974. Studies on the Biology of the Chrysopidae. IV. A field and laboratory study of the seasonal cycle of Chrysopa carnea Steph. in Central Illinois. Trans. Amer. Entomol. Soc. 100: 437-512.

Sмith, R. C. 1922. The biology of the Chrysopidae. Mem. Cornell Univ. Agr. Exp. Sta. 58: 1291-1372. 
TAuber, C. A. 1969. Taxonomy and biology of the lacewing genus Meleoma (Neuroptera: Chrysopidae). Univ. Calif. Publ. Ent. 58: 1-62.

TAYLOR, C. P. 1981. Contribution of compound eyes and ocelli to the steering of locusts in flight. I. Behavioral analysis. J. Exp. Biol. 93: 1-18.

Toschi, C. A. 1965. The taxonomy, life histories, and mating behavior of the green lacewings of Strawberry Canyon. Hilgardia 36: 391-431. 

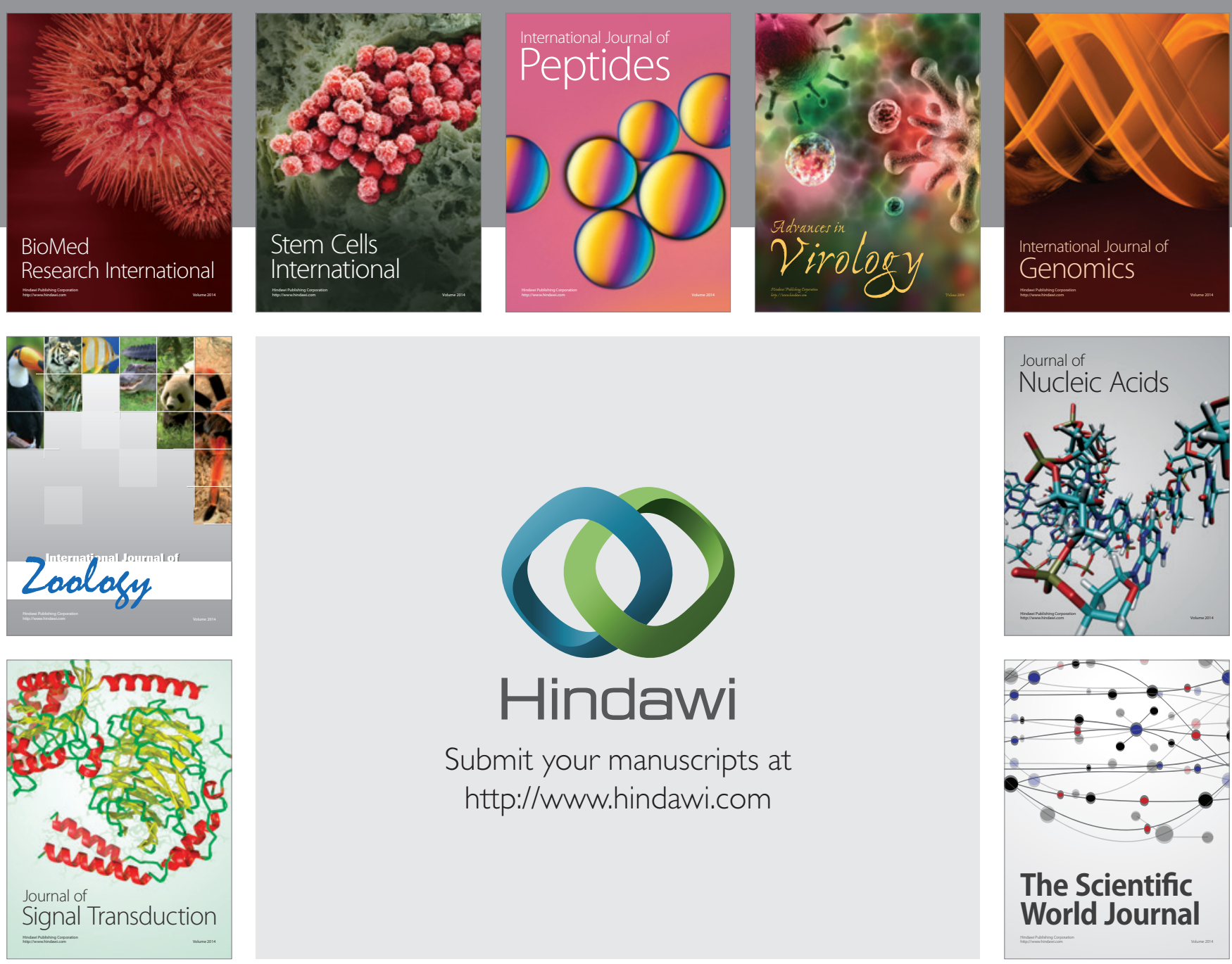

Submit your manuscripts at

http://www.hindawi.com
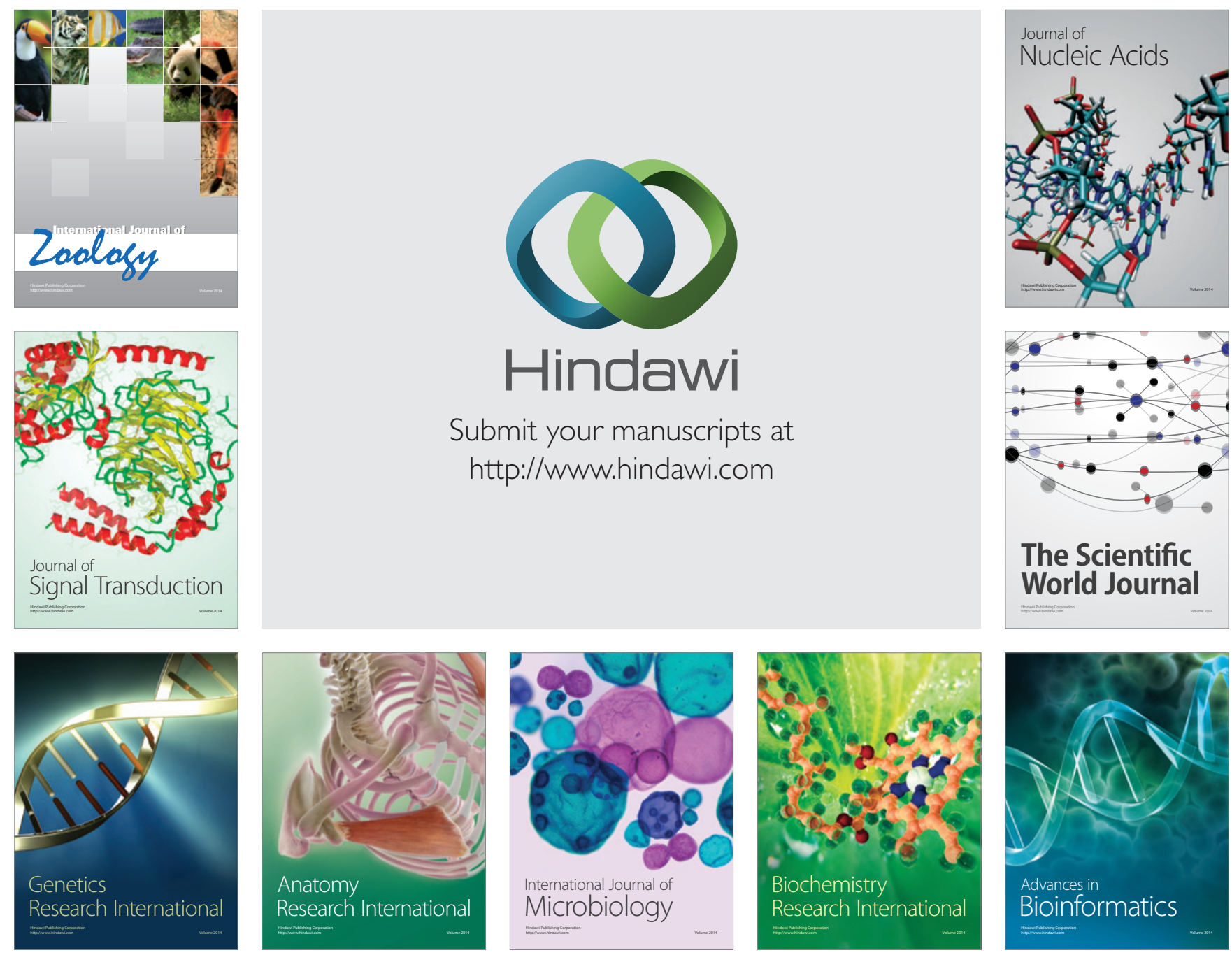

The Scientific World Journal
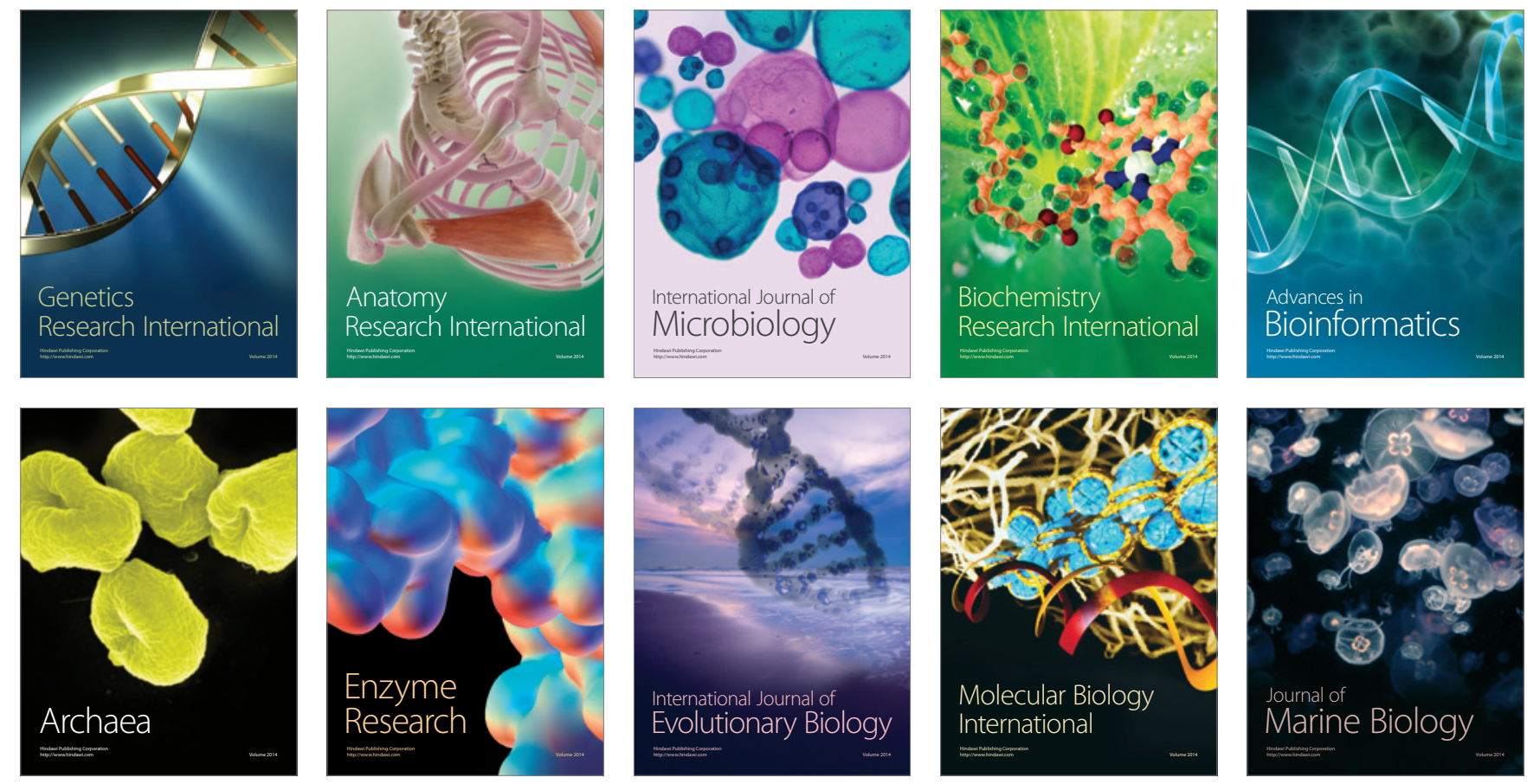